\title{
FAKTOR-FAKTOR YANG BERHUBUNGAN DENGAN KUNJUNGAN NEONATUS DI WILAYAH KERJA PUSKESMAS LUBUK KILANGAN
}

\author{
Zuraida \\ STIKes Fort De Kock, Bukittinggi \\ email: zuraida_jauza@yahoo.co.id
}

Submitted: 05-12-2016, Reviewer: 07-12-2016, Accepted: 07-12-2016

\begin{abstract}
ABSTRAK
Berdasarkan survei Riset Kesehatan Dasar Depkes 2014, kematian bayi baru lahir (neonatus) merupakan penyumbang kematian terbesar pada tingginya angka kematian bayi (AKB).Target kunjungan neonatal pada tahun 2015 adalah 90\%, sedangkan berdasarkan hasil studi pendahuluan di Puskesmas Lubuk Kilangan Padang didapatkan pencapaian target tersebut pada tahun 2015 belum tercapai maksimal.Tujuan penelitian ini untuk mengetahui faktor-faktor yang berhubungan dengan kunjungan neonatus di wilayah kerja Puskesmas Lubuk Kilangan Padang tahun 2016.Jenis penelitian adalah deskriptif analitik dengan desain cross sectional. Populasi penelitian adalah seluruh ibu yang mempunyai bayi berumur lebih dari 28 hari di wilayah kerja Puskesmas Lubuk Kilangan Padang yang melakukan kunjungan neonatus yaitu 56 orang. Teknik pengambilan sampel dilakukan dengan menggunakan teknik Total Sampling.Data diperoleh dengan metode pengisian kuesioner.Analisa data menggunakan uji statistic chi square.Hasil penelitian didapatkan 57,1\% responden yang memiliki pengetahuan yang rendah, 55,4\% responden yang memiliki sikap negatif, $67,9 \%$ responden yang tidak bekerja, 55,4\% responden yang kunjungan neonatusnya tidak tercapai. Hasil uji statistic menunjukkan ada hubungan antara pengetahuan $(p=0,009)$, sikap $(p=0,004)$, pekerjaan $(0,000)$ dengan kunjungan neonatus.Disimpulkan lebih separuh ibu yang melakukan kunjungan neonatus tidak tercapai yang disebabkan karena pengetahuan yang rendah, sikap yang negatif, dan ibu tidak bekerja. Diharapkan pada pihak petugas Puskesmas agar diupayakan peningkatan kerjasama yang baik dengan pihak PKK, Kader Posyandu dalam rangka pemberian informasi tentang pentingnya kunjungan neonatus, dan petugas Puskesmas menyarankan pada ibu hamil dapat melakukan kunjungan Neonatus.
\end{abstract}

\section{Kata Kunci : Pengetahuan, Sikap, Pekerjaan, Kunjungan Neonatus}

\section{ABSTRACT}

Based on the survey of Health Research done by the Ministry of Health in 2014, neonatal in the biggest contributor to the hight infant mortality rate (IMR). Target of neonatal visits in 2015 were 90\%, however based on the results of the preliminary study on PHC Lubuk Kilangan, the targeted achievement of neonatal visits in 2015 had not been maximal. The objective of this study was to determine the factors associated in the neonatal visits in Lubuk Kilangan PHC of Padang in 2016.This type of research is analytic descriftives with cross sectional design. The study population were all mothers with infants aged more than 28 days in the work area of Lubuk Kilangan PHC to perform neonatal visits as 56 people. The sampling technique is done by using Total Sampling. Data obtained by the method of filling out the questionnaire. Data were analyzed using chi square test.The result showed 57,1\% respondents had low knowledge, 55,4\% respondents had negative attitude, 67,9\% respondents does not work, 55,4 neonatal visits not achieved. Statistical analysis showed there is relationship between knowledge ( $p$ value $=0,009)$, attitude $(p$ value $=0,004)$, worked ( $p$ value $=0,000$ ) with neonatal visits.It is concluded that more than half of the women to neonatal visits not achieved caused by poor knowledge, negative attitudes and does not work. It is then expected that the health center staff should boost the good cooperation with the PKK, and PHC workers in order to provide information about the importance of neonatal visits. In addition, the health center staff an advise pregnant women to perform neonatal visits.

Keywords: Knowledge, attitude, worked, neonatal visits 


\section{PENDAHULUAN}

Neonatal adalah cabang bayi baru lahir hingga berumur 4 minggu (kamus dorland, 2005). Neonatus adalah bayi yang baru mengalami proses kelahiran dan harus menyesuaikan diri dari kehidupan intra uterine ke kehidupan ekstra uterin. Neonatus adalah masa kehidupan pertama diluar rahim sampai dengan usia 28 hari, dimana terjadi perubahan yang sangat besar dari kehidupan di dalam rahim menjadi diluar rahim (Muslihatun 2010).

Kunjungan neonatus adalah pelayanan sesuai standar yang diberikan tenaga kesehatan yang kompeten kepada neonatus, sedikitnya 3 (tiga) kali selama periode 0-28 hari setelah lahir, baik di fasilitas kesehatan maupun kunjungan rumah yaitu: Kunjungan Neonatal ke-1 (KN1) dilakukan pada kurun waktu 6-48 jam setelah lahir, Kunjungan Neonatal ke-2 (KN2) dilakukan pada kurun waktu hari 3-7 setelah lahir, Kunjungan Neonatal ke-3 (KN3) dilakukan pada kurun waktu hari 828 setelah lahir, baik di fasilitas kesehatan maupun kunjungan rumah (Dinkes 2012).

Tujuan dari kunjungan neonatus, yaitu melakukan pemeriksaan ulang pada ayi baru lahir, meninjau penyuluhan dan pedoman antisipasi bersama orang tua, mengidentifikasi gejala penyakit, serta mendidik dan mendukung orang tua.Tujuan kunjungan neonatal adalah untuk meningkatkan akses neonatus terhadap pelayanan kesehatan dasar, mengetahui sedini mungkin bila terdapat kelainan pada bayi atau mengalami masalah (Yulifah 2013).

Menurut laporan kelompok kerja World Health Organization (WHO) ada bulan April 2012, dari 8,1 juta kematian bayi di dunia, $48 \%$ adalah kematian neonatus. Dari seluruh kematian neonatus sekitar $60 \%$ merupakan kematian bayi umur kurang dari 7 hari dan kematian bayi umur lebih dari 7 hari akibat gangguan perinatal. Sekitar $42 \%$ kematian neonatus disebabkan oleh infeksi seperti tetanus neonatorum, sepsis, meningitis, pneumonia dan diare (Darmawan 2012).
Kematian neonatal dapat dicegah dengan pelayanan minimum neonatal. Sebagian besar dari kematian neonatal dapat dicegah dengan pemberian paket minimum perawatan neonatal. Namun, sekitar 3 juta neonatus meninggal setiap bulan secara global karena kurangnya perawatan yang tepat. Situasi ini adalah yang terburuk di Ethiopia (Fantahun, 2015).

Berdasarkan Survey Demografi dan Kesehatan Indonesia (SDKI) (2014) lebih dari tiga perempat dari semua kematian balita terjadi dalam tahun pertama kehidupan anak dan mayoritas kematian bayi terjadi pada periode neonatus (Kemenkes RI, 2014). Masa perinatal dan neonatal merupakan masa yang kritis bagi kehidupan bayi. Dua pertiga kematian bayi terjadi dalam 4 minggu setelah persalinan dan $60 \%$ kematian bayi baru lahir terjadi dalam waktu 7 hari setelah lahir. Faktor yang menyebabkan kematian perinatal antara lain perdarahan, hipertensi, infeksi, kelainan preterm atau BBLR, asfiksia dan hipotermia (Afifah,2013).

Di Indonesia tercatat cakupan kunjungan Neonatus (KN) tertinggi berada di Propinsi Jawa Tengah yaitu sebesar 95,41\%, dan terendah berada di Propinsi Papua yaitu sebesar 25,41\%. Dan Propinsi Sumatra Barat sebesar 80,28\% (Kemenkes RI 2014). Di Sumatra Barat tercatat cakupan Kunjungan Neonatus (KN) tertinggi berada di Kabupaten Pasaman yaitu sebesar $100 \%$, dan terendah berada di Kabupaten Mentawai yaitu sebesar $64,5 \%$. Dan Kota Padang yaitu sebesar 76,8\% (Profil Kesehatan Prof.Sumbar 2014).

Di Kota Padang tercatat cakupan Kunjungan Neonatus (KN) pada 3 Puskesmas yang terendah yaitu berada di Puskesmas Lubuk Begalung, Puskesmas Pengambiran dan Puskesmas Lubuk Kilangan. Puskesmas Lubuk Begalung sebesar 74\%, Puskesmas Pengambiran 66\%, dan Puskesmas Lubuk Kilangan sebesar 54\% (Dinkes 2015). Dari cakupan kunjungan di Kota Padang, Puskesmas Lubuk Kilangan berada diurutan terendah yaitu 54\%. Sedangkan standar kunjungan 
neonatal adalah 90\%. Jadi Puskesmas Lubuk Kilangan belum memenuhi standar dalam kunjungan neonatalnya.

Menurut standar asuhan kebidanan semua bayi yang lahir sehat harus mendapatkan asuhan yang komprehensif sampai usia satu bulan. Asuhan ini bisa diperoleh melalui kunjungan rumah sebanyak tiga kali, yaitu KN1 pada 48 jam pertama, KN2 pada hari ke 3 sampai ke 7 dan KN3 setelah satu minggu sampai hari ke 28 sesuai dengan kebutuhan masingmasing keluarga (Depkes RI 2013).

Pengetahuan Ibu mengenai pemeriksaan saat kunjungan neonatus sangat di perlukan, mengingat ibu adalah mitra bagi tenaga kesehatan. Sebagai orang yang terdekat dengan neonatus dan sebagai mitra bidan/tenaga kesehatan. Ibu semestinya mengetahui pemeriksaan atau pelayanan apa saja yang dilakukan oleh tenaga kesehatan sehingga dapat bekerja sama dengan bidan ketika bidan melakukan pemeriksaan saat kunjungan neonatus (Rosita 2012).

Sikap adalah bagaimana pendapat atau penilaian orang atau responden terhadap hal yang terkait dengan kesehatan, sehat-sakit dan faktor yang terkait dengan faktor resiko kesehatan. Jadi sikap dapat berubah-rubah dalam situasi yang memenuhi syarat (Afifah 2013).

Ibu dengan pekerjaan yang rendah akan berdampak terhadap cara perawatan bayi baru lahir. Sebuah studi deskreptif tentang pengetahuan dan sikap terhadap perawatan neonatus di Selatan India menunjukkan bahwa ibu dengan pekerjaan yang baik akan berpengaruh terhadap perawatan neonatus yang baik, hal ini berkaitan dengan pendidikan dan pengetahuan ibu (Rosita 2012).

Berdasarkan penelitian Anggarsih Sri Wahyuni tahun 2010 dengan judul "Gambaran Faktor yang Menyebabkan Rendahnya Cakupan Kunjungan Neonatus $(\mathrm{KN})$ di Desa Gunung Katun Kecamatan Baradatu Kabupaten Way Kanan tahun 2010". Dari 51 responden, 17 responden patuh dalam melakukan kunjungan neonatus, sedangkan sisanya yaitu 34 responden tidak patuh dalam melakukan kunjungan neonatus.

Dari survey awal yang dilakukan di wilayah kerja Puskesmas Lubuk Kilangan, dari 10 ibu yang melakukan kunjungan neonatus hanya 4 ibu yang patuh dalam melakukan kunjungan, sedangkan sisanya yaitu 6 ibu yang tidak patuh dalam melakukan kunjungan neonatus. Dilihat dari variabel independennya, dari segi pengetahuan hanya $4 \mathrm{ibu}$ yang memiliki pengetahuan yang tinggi dan 6 ibu memiliki pengetahuan yang rendah, dari segi sikap hanya $3 \mathrm{ibu}$ yang memiliki sikap positif dan 7 ibu lagi memiliki sikap yang negatif, dilihat dari segi pekerjaan hanya 1 orang ibu yang bekerja selebihnya 9 ibu tidak bekerja.

\section{METODE PENELITIAN}

Penelitian ini merupakan jenis penelitian deskripsi analitik yang dilakukan melalui pendekatan cross sectional yaitu suatu penelitian yang mempelajari hubungan variabel independent (pengetahuan, sikap dan pekerjaan) dan dependent (Kunjungan Neonatus) dengan cara pendekatan observasi dan pengumpulan data dalam waktu yang bersamaan.Penelitian ini dilakukan di Puskesmas Lubuk Kilangan Padang dalam rentang waktu bulan Maret-April 2016. Populasi dalam penelitian ini adalah seluruh ibu yang mempunyai bayi berumur lebih dari 28 hari yang berdomisili di wilayah kerja Puskesmas Lubuk Kilangan Padang yang melakukan kunjungan neonatus pada bulan Maret tahun 2016 sebanyak 56 orang.Teknik pengambilan sampel pada penelitian ini menggunakan teknik Total Sampling yaitu teknik penentuan sampel dengan mengambil seluruh anggota populasi sebagai responden atau sampel.Jadi sampel yang diambil pada penelitian ini berjumlah 56 orang.Pada penelitian ini data diperoleh dari data yang ada dipuskesmas dan data yang ada pada bidan.Setelah data didapat, kemudian datadiedit, coding, enty dan tabulating serta 
diolahdengan menggunakan analisa univariat untukmengambarkan distribusi frekuensi.

\section{HASIL DAN PEMBAHASAN}

Pada hasil penelitian ini penuliskan memaparkan pengetahuan, sikap pekerjaan, dan kunjungan neonatus di puskesmas lubuk kilangan

\section{Distribusi Frekuensi Pengetahuan}

Tabel 1

Distribusi Frekuensi Pengetahuan Ibu tentang Kunjungan Neonatus Di Wilayah Kerja Puskesmas Lubuk Kilangan

\begin{tabular}{cccc}
\hline No & Pengetahuan & f & \% \\
\hline & & & \\
1. & Rendah & 32 & 57,1 \\
2. & Tinggi & 24 & 42,9 \\
& Jumlah & 56 & 100 \\
\hline
\end{tabular}

Dari tabel diatas dapat dilihat bahwa dari 56 responden terdapat 32 responden $(57,1 \%)$ yang mempunyai pengetahuan tinggi tentang kunjungan neonatus.

Pengetahuan adalah hasil dari tahu, ini terjadi setelah orang melakukan penginderaan terhadap suatu objek tertentu melalui mata dan telinga (Notoatmodjo 2010,p.50). Dari hasil pengalaman dan penelitian terbukti bahwa perilaku yang didasari oleh pengetahuan akan lebih langgeng dari pada perilaku yang tidak didasari oleh pengetahuan (Notoatmodjo 2010).

Pengetahuan responden juga dipengaruhi oleh faktor pendidikan yang mayoritas SMA. Menurut Sari (2009), pendidikan suatu usaha untuk mengembangkan kepribadian dan kemampuan didalam dan diluar sekolah dan berlangsung seumur hidup. Pendidikan mempengaruhi pengetahuan, makin tinggi pendidikan seseorang makin mudah orang tersebut untuk menerima informasi. Menurut Notoatmodjo (2010), pendidikan suatu kegiatan atau proses pembelajaran untuk mengembangkan atau meningkatkan kemampuan tertentu sehingga sasaran pendidikan ini dapat berdiri sendiri. Makin tinggi pendidikan seseorang maka makin tinggi pula pengetahuan yang dimiliki orang tersebut.

Hasil penelitian yang saya lakukan ini sejalan dengan penelitian yang dilakukan oleh Maria (2014) gambaran pengetahuan ibu yang mempunyai bayi usia 0-28 hari tentang kunjungan neonatus di Puskesmas Padan Kandi Kabupaten 50 kota, yang menemukan bahwa sebagian besar $(51,4 \%) \mathrm{ibu}$ berpengetahuan rendah tentang kunjungan neonatus.

Menurut analisa peneliti, pengetahuan responden yang rendah tentang neonatus adalah karena kurangnya informasi yang diperoleh ibu baik melalui informasi yang diterima dari tenaga kesehatan, departemen kesehatan, pemerintah daerah, dan organisasi dibidang kesehatan dan kader- kader kesehatan maupun informasi dari media cetak dan elektronik, melalui koran, majalah, iklan, radio, dan $\mathrm{TV}$, dan responden hanya menunggu informasi dari petugas jarang sekali responden yang punya keinginan untuk berkonsultasi khusus tentang kunjungan neonatus pada petugas kesehatan. Sementara responden yang memiliki pengetahuan tinggi dapat tercapai dengan adanya informasi yang diperoleh dari bidan, tenaga kesehatan lain dan kader kesehatan, dan adanya informasi yang dilihat berupa iklan di media elektronik.

\section{Distribusi Frekuensi Sikap}

Tabel 2

Distribusi Frekuensi Sikap Ibu tentang Kunjungan Neonatus Di Wilayah Kerja Puskesmas

Lubuk Kilangan

\begin{tabular}{cccc}
\hline No & Sikap & f & \% \\
\hline 1. & Negatif & 31 & 55,4 \\
2. & Positif & 25 & 44,6 \\
& Jumlah & 56 & 100 \\
\hline
\end{tabular}

Dari tabel diatas dapat dilihat bahwa dari 56 responden terdapat 31 responden $(55,4 \%)$ yang mempunyai sikap negatif terhadap kunjungan neonatus. 
Sikap bukan suatu tindakan atau aktifitas, tetapi merupakan predisposisi tindakan perilaku.Sikap ini merupakan reaksi tertutup seseorang terhadap objek yang dapat meliputi perasaan mendukung atau memihak (favorable) maupun perasaan tidak mendukung atau menolak (unforable) pada suatu objek (azwar, 2010).

Hasil penelitian yang saya lakukan ini sejalan dengan penelitian yang dilakukan oleh Afifah (2013) tentang gambaran pengetahuan, sikap, dan praktik ibu post natal terhadap kunjungan neonatus di BPS Hj Sri Wahyuni kota Semarang, yang menemukan bahwa sebagian besar $(57,5 \%)$ ibu bersikap negatif terhadap kunjungan neonatus.

Menurut analisa peneliti, ibu yang memiliki sikap positif terhadap kunjungan neonatus disebabkan karena ibu tersebut memiliki pemahaman yang baik tentang manfaat dari kunjungan neonatus tersebut, sedangkan ibu yang memiliki sikap negatif terhadap kunjungan neonatus tidak memiliki pemahaman yang baik terhadap kunjungan neonatus hal ini disebabkan karena ibu beranggapan bila membawa bayi ke petugas kesehatan nanti bayi nya akan disuntik dan hal ini si bayi akan menjadi demam ibu takut bayi nya akan menjadi rewel dan ibu beranggapan kunjungan neonatus tidak perlu dilakukan karena membawa bayi di usia kurang dari satu bulan akan membahayakan bayi nya sehingga kunjungan neonatus tidak lah penting buat bayi nya, di tambah dengan dukungan keluarga atau suami yang kurang menganggap

kunjunganneonatus merepotkan dan memerlukan waktu yang lama.

\section{Distribusi Frekuensi Pekerjaan}

Tabel 3

\begin{tabular}{|c|c|c|c|}
\hline \multicolumn{4}{|c|}{$\begin{array}{c}\text { Distribusi Frekuensi Pekerjaan Ibu tentang } \\
\text { Kunjungan Neonatus Di Wilayah Kerja } \\
\text { Puskesmas Lubuk Kilangan }\end{array}$} \\
\hline No & Pekerjaan & $\mathbf{f}$ & $\%$ \\
\hline 1. & Tidak Bekerja & 38 & 67,9 \\
\hline \multirow[t]{2}{*}{2.} & Bekerja & 18 & 32,1 \\
\hline & Jumlah & 56 & 100 \\
\hline
\end{tabular}

Dari tabel diatas dapat dilihat bahwa dari 56 responden terdapat 38 responden $(67,9 \%)$ yang tidak bekerja sehingga ibu yang tidak bekerja berpengaruh bagi kunjungan neonatusnya.

Bekerja disini adalah seseorang yang bekerja akan sering berinteraksi dengan orang lain sehingga akan memiliki pengetahuan yang baik, pengalaman bekerja akan dapat mengembangkan kemampuan dalam mengambil keputusan yang merupakan keterpaduan menalar secara ilmiah (Notoatmodjo 2010).

Hasil penelitian yang saya lakukan ini sejalan dengan penelitian yang dilakukan oleh Darmawan (2011) tentang hubungan pengetahuan dan pekerjaan ibu dengan kunjungan neonatus di wilayah kerja Puskesmas Pasirlangu Kabupaten Bandung Barat, yang menemukan bahwa sebagian besar $(561,9 \%)$ ibu yang tidak bekerja mengalami kunj 46 neonatus yang tidak tercapai.

Menurut analisa p........ ibu yang memiliki pekerjaan akan memiliki pemahaman tentang kunjungan neonatus, karena pekerjaan dapat mempengaruhi pengetahuan seseorang, dimana responden yang hanyamenjadi ibu rumah tangga selalu terfokus pada pekerjaan rumah tangga dan mengurus anak, hal ini bisa saja menjadi penyebab ibu rumah tangga tidak mendapatkan informasi tentang kunjungan neonatus dari berbagai sumber, misalnya: pengalaman (orang tua, saudara, kerabat/tetangga) media massa (TV, radio, internet) dan media cetak (koran, majalah).Ibu yang bekerja cenderung memiliki banyak teman yang dapat berbagi cerita tentang pengalaman terhadap kunjungan neonatus. 


\section{Distribusi Frekuensi Kunjungan Neonatus}

Tabel 4

Distribusi Frekuensi Kunjungan Neonatus DiWilayah Kerja Puskesmas Lubuk Kilangan

\begin{tabular}{cccc}
\hline No & $\begin{array}{c}\text { Kunjungan } \\
\text { Neonatus }\end{array}$ & f & \% \\
\hline 1. & Tidak Tercapai & 31 & 55,4 \\
2. & Tercapai & 25 & 44,6 \\
& Jumlah & 78 & 100 \\
\hline
\end{tabular}

Berdasarkan tabel diatas diketahui dari 56 responden lebih separuh $(55,4 \%)$ termasuk kategori tidak tercapai dalam kunjungan neonatus.

Kunjungan neonatus adalah kontak neonatus dengan tenaga kesehatan minimal dua kali untuk mendapatkan pelayanan dan pemeriksaan kesehatan neonatus, baik didalam maupun diluar gedung puskesmas, termasuk bidan di desa, polindes dan kunjungan kerumah.Bentuk pelayanan tersebut meliputi pelayanan kesehatan neonatal dasar (tindakan resusitasi, pencegahan infeksi berupa perawatan mata, tali pusat, kulit dan pemberian imunisasi) pemberian vitamin $\mathrm{K}$ dan penyuluhan neonatus di rumah menggunakan buku KIA (Depkes RI, 2013).

Hasil penelitian yang saya lakukan ini sejalan dengan penelitian yang dilakukan oleh Linggawati (2012) tentang hubungan pengetahuan dan sikap ibu dengan kunjungan neonatal di wilayah kerja Puskesmas Kota Tais menemukan lebih separuh $(61 \%)$ ibu tidak teratur melakukan kunjungan neonatus.

Menurut analisa peneliti kunjungan neonatus ini disebabkan karena beberapa faktor diantaranya tingkat pengetahuan ibu tentang kunjungan neonatus tersebut, dan sikap ibu terhadap kunjungan neonatus tersebut.Ibu yang berpengetahuan tinggi dan bekerja cenderung bersikap positif dalam melakukan kunjungan neonatus dibandingkan ibu yang memiliki pengetahuan rendah dan tidak bekerja cenderung bersikap negatif dalam melakukan kunjungan neonatus.
Menurut analisa peneliti tercapainya dalam melakukan kunjungan neonatus ini disebabkan karena sikap ibu terhadap kunjungan neonatus tersebut.Ibu yang berpengetahuan tinggi dan bekerja cenderung bersikap positif dan melakukan kunjungan neonatus dibandingkan ibu yang memiliki pengetahuan rendah dan tidak bekerja cenderung bersikap negatif dalam melakukan kunjungan neonatus tersebut. Adapun sikap ibu dipengaruhi faktor budaya dan pengalaman bayi nya terdahulu atau pengalaman tetangga bila ibu membawa bayinya ke petugas kesehatan bayi akan di suntik dan akan menyebabkan demam dan rewel padahal bayi nya masih kecil itu alasan ibu tidak membawa bayi nya ke petugas kesehatan. Selain itu kunjungan neonatus juga dipengaruhi letak wilayah masih ada wilayah sulit dari Puskesmas tersebut.

\section{Hubungan Pengetahuan dengan Kunjungan Neonatus}

Tabel 5

Hubungan Pengetahuan Dengan Kunjungan

Neonatus di Wilayah Kerja Puskesmas Lubuk Kilangan

\begin{tabular}{|c|c|c|c|c|c|c|c|c|}
\hline \multirow{3}{*}{$\begin{array}{l}\text { Pengetahu } \\
\text { an }\end{array}$} & \multicolumn{4}{|c|}{ Kunjungan Neonatus } & \multicolumn{2}{|c|}{ Jumlah } & \multirow{3}{*}{$\begin{array}{c}\text { P } \\
\text { valu } \\
\text { e }\end{array}$} & \multirow[t]{3}{*}{ OR } \\
\hline & \multicolumn{2}{|c|}{$\begin{array}{c}\text { Tidak } \\
\text { Tercapai }\end{array}$} & \multicolumn{2}{|c|}{ Tercapai } & & & & \\
\hline & $\mathbf{n}$ & $\%$ & $\mathbf{n}$ & $\%$ & $\mathbf{N}$ & $\%$ & & \\
\hline Rendah & 23 & 71.9 & 9 & 28,1 & 32 & 10 & 0.00 & 5.111 \\
\hline Tinggi & 8 & 33.3 & 16 & 66.7 & 24 & $\begin{array}{l}0 \\
10\end{array}$ & 9 & \\
\hline Total & 31 & 55.4 & 25 & 44.6 & 56 & $\begin{array}{c}0 \\
10 \\
0\end{array}$ & & 16.08) \\
\hline
\end{tabular}

Berdasarkan tabel 5 dapat diketahui bahwa dari 32 responden yang memiliki pengetahuan rendah terdapat 23 orang (71,9\%)mengalami kunjungan neonatus yang tidak tercapai. Hasil uji diperoleh $\mathrm{p}$ value $=0,009$, dapat disimpulkan terdapat hubungan bermakna antara pengetahuan dengan kunjungan neonatus yang dengan $\mathrm{OR}=5,111$ artinya ibu yang memiliki pengetahuan rendah berpeluang $5,111 \mathrm{kali}$ lebih beresiko tidak melakukan kunjungan neonatus dibandingkan dengan ibu yang berpengetahuan tinggi.

Hasil penelitian yang saya lakukan ini sesuai dengan teori yang menyatakan bahwa pengetahuan merupakan dominan 
yang sangat penting untuk terbentuknya tindakan seseorang (overbehavior), dimana pengetahuan akan mendasari individu berfikir dan berbuat sesuatu. Perilaku yang didasari oleh pengetahuan akan lebih langgeng dari pada perilaku yang didasari oleh pengetahuan. Apabila penerimaan perilaku baru didasari oleh pengetahuan, kesadaran dan sikap positif maka

Hasil penelitian yang saya lakukan ini sejalan dengan penelitian yang dilakukan oleh Darmawan (2011) tentang hubungan pengetahuan dan Pekerjaan ibu dengan kunjungan neonatus di wilayah kerja Puskesmas Pasirlangu Kabupaten Bandung Barat, yang menemukan terdapat hubungan pengetahuan ibu dengan frekuensi kunjungan Neonatus di wilayah kerja Puskesmas Pasirlangu Kabupaten Bandung Barat dengan $\mathrm{p}$ value $=0,0001$.

Menurut analisa peneliti dalam hal ini responden yang memiliki pengetahuan tinggi tentunya telah mengetahui tentang segala sesuatu yang berhubungan dengan kunjungan neonates.Dari pengetahuan yang ada tersebut maka responden dapat melakukan kunjungan neonatus bagi kesehatan bayi nya.Sebaliknya responden yang memiliki pengetahuan rendah tentunya kurang mengetahui segala sesuatu yang berhubungan dengan kunjungan neonatus, sehingga mereka tidak dapat melakukan kunjungan neonatus.

Cukup banyak responden yang memiliki pengetahuan rendah yang tidak memanfaatkan kunjungan neonatus disebabkan oleh adanya informasi yang kurang diterima dari tenaga kesehatan dan kader kesehatan, bahwa kunjungan neonatus tersebut dilakukan tiga kali sejak bayi berumur 0-28 hari yang dilakukan oleh tenaga kesehatan.selain itu responden juga tidak memanfaatkan fasilitas yang ada seperti tidak mengikuti penyuluhan yang diberikan oleh tenaga kesehatan sehingga minimnya pengetahuan ibu tentang kunjungan neonatus.

Sedangkan responden yang memiliki pengetahuan tinggi tetapi mengalami kunjungan neonatus yang tidak tercapai, menurut analisa peneliti responden masih mempercayai budaya yang tidak membolehkan bayi melakukan kunjungan neonatus.Responden memiliki pengalaman pada anak terdahulu sehingga tidak membawa anak untuk melakukan kunjungan neonatus.Misalnya pada anak terdahulu setelah dibawa ke posyandu anak di beri imunisasi dan langsung demam, itu membuat ibu menjadi khawatir untuk membawa anaknya lagi ke posyandu.

\section{HubunganSikap Dengan Kunjungan Neonatus}

Tabel 6

Hubungan Sikap Ibu dengan Kunjungan Neonatus di Wilayah Kerja Puskesmas Lubuk Kilangan

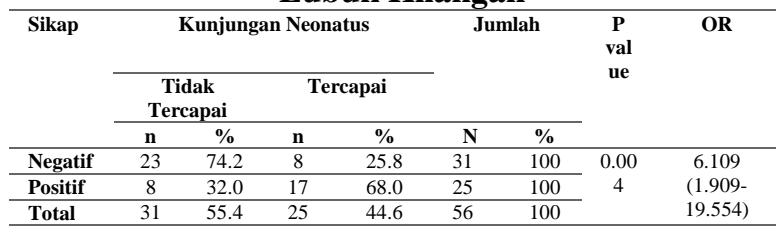

Berdasarkan tabel 6 dapat diketahui bahwa dari 31 responden yang bersifat negatif terdapat 23 orang $(74,2 \%)$ mengalami kunjungan neonatus yang tidak tercapai. Hasil uji diperoleh nilai $\mathrm{p}$ value $=$ 0,004, dapat disimpulkan terdapat hubungan bermakna antara sikap dengan kunjungan neonatus dengan $\mathrm{OR}=61,09$ artinya ibu yang memiliki sikap negatif berpeluang 61,09 kali lebih beresiko tidak melakukan kunjungan neonatus yang tidak tercapai di bandingkan dengan ibu bersikap positif.

Sikap merupakan suatu reaksi (respon) yang masih tertutup dari responden tersebut sangat dipengaruhi oleh pengetahuannya tentang kunjungan neonatus, keyakinan, emosi dan sampai pada mempertahankan sikapnya terhadap manfaat kunjungan neonatus. Pengukuran sikap dapat dilakukan secaralangsung atau tidak langsung. Secara langsung dapat dinyatakan dengan mengemukakan bagaimana pendapat atau pernyataan responden terhadap suatu objek, sedangkan secara tidak langsung dapat dengan 
menggunakan kuesioner (Notoatmodjo, 2007).

Hasil penelitian yang saya lakukan ini sejalan dengan penelitian yang dilakukan oleh Linggawati (2012) tentang hubungan pengetahuan dan sikap ibu dengan kunjungan neonatal di wilayah kerja Puskesmas Kota Tais dengan $\mathrm{p}$ value = 0,001

Menurut analisa peneliti, ibu yang memiliki sikap positif terhadap kunjungan neonatus akan lebih teratur melakukan kunjungan neonatus dibandingkan dengan ibu yang bersikap negatif terhadap kunjungan neonatus .Hal ini lebih di karena sikap ibu terhadap kunjungan neonatus, sikap ibu ini lah yang menentukan tindakan seorang ibu untuk memutuskan sesuatu. Hal ini disebabkan karena ibu beranggapan bila membawa bayi ke petugas kesehatan nanti bayi nya akan disuntik dan hal ini si bayi akan menjadi demam ibu takut bayinya akan menjadi demam ibu takut bayinya akan menjadi rewel dan ibu beranggapan kunjungan neonatus tidak perlu dilakukan karena membawa bayi di usia kurang dari satu bulan akan membahayakan bayi nya sehingga kunjungan neonatus tidak lah penting buat bayi nya, ditambah dengan dukungan keluarga atau suami yang kurang menganggap kunjungan neonatus merepotkan dan memerlukan waktu yang lama.

Sedangkan responden yang memiliki sikap positif tetapi mengalami kunjungan neonatus yang tidak tercapai, menurut asumsi peneliti responden kurang yakin bahwa anak perlu melakukan kunjungan neonatus. Sikap seseorang belum tentu terwujud dalam tindakan, sebab untuk terwujudnya tindakan perlu faktor lain. Misalnya rumah ibu dengan tempat kunjungan neonatus jauh dan tidak ada yang bisa mengantarkan ibu, jadi karena faktor inilah yang menyebabkan ibu tidak melakukan kunjungan neonatus.

\section{Hubungan Pekerjaan dengan Kunjungan Neonatus}

Tabel 7

Hubungan Pekerjaan Ibu dengan Kunjungan Neonatus di Wilayah Kerja Puskesmas Lubuk Kilangan

\begin{tabular}{|c|c|c|c|c|c|c|c|c|}
\hline \multirow{3}{*}{ Pekerjaan } & \multicolumn{4}{|c|}{ Kunjungan Neonatus } & \multicolumn{2}{|c|}{ Jumlah } & \multirow{3}{*}{$\begin{array}{c}\text { Pval } \\
\text { ue }\end{array}$} & \multirow[t]{3}{*}{$\mathbf{O R}$} \\
\hline & \multicolumn{2}{|c|}{$\begin{array}{c}\text { Tidak } \\
\text { Tercapai }\end{array}$} & \multicolumn{2}{|c|}{ Tercapai } & & & & \\
\hline & $\mathbf{n}$ & $\%$ & $\mathbf{n}$ & $\%$ & $\mathbf{N}$ & $\%$ & & \\
\hline Tidak & 30 & 78.9 & 8 & 21.1 & 38 & 100 & 0.00 & 63.750 \\
\hline Bekerja & & & & & & & 0 & $(7.335-$ \\
\hline Bekerja & 1 & 5.6 & 17 & 94.4 & 18 & 100 & & $\begin{array}{c}554.07 \\
\text { 3) }\end{array}$ \\
\hline Total & 31 & 55.4 & 25 & 44.6 & 56 & 100 & & \\
\hline
\end{tabular}

Berdasarkan tabel 7 dapat diketahui bahwa dari 38 responden yang tidak bekerja terdapat 30 orang $(78,9 \%)$ mengalami kunjungan neonatus yang tidak tercapai. Hasil uji diperoleh nilai $\mathrm{p}$ value $=0,000$, dapat disimpulkan terdapat hubungan bermakna antara pekerjaan dengan kunjungan neonatus dengan $\mathrm{OR}=63,750$ artinya ibu yang tidak bekerja berpeluang 63,750 kali lebih beresiko tidak melakukan kunjungan neonatus yang tidak tercapai di bandingkan dengan ibu yang bekerja.

Hasil penelitian yang saya lakukan ini sesuai dengan teori yang menyatakan bahwa faktor pekerjaan juga

mempengaruhi pengetahuan. Seseorang yang bekerja pengetahuannya akan lebih luas dari pada seseorang yang tidak bekerja, karena dengan bekerja seseorang akan banyak mempunyai informasi (Khusniyah,2011). Menurut Sakernas (Notoatmodjo, 2012) jenis pekerjaan yaitu: pedagang, buruh/tani, PNS,TNI/Polri, wiraswasta.

Hasil penelitian yang saya lakukan ini sejalan dengan penelitian yang dilakukan oleh Darmawan (2011) tentang hubungan pengetahuan dan Pekerjaan ibu dengan kunjungan neonatus di wilayah kerja Puskesmas Pasirlangu Kabupaten Bandung Barat, yang menemukan terdapat hubungan pekerjaan ibu dengan frekuensi kunjungan Neonatus di wilayah kerja Puskesmas Tapan Pesisir Selatan dengan $\mathrm{p}$ value $=0,002$. 
Menurut analisa peneliti, ibu yang memiliki pekerjaan akan memiliki pemahaman tentang kunjungan neonatus, karena pekerjaan dapat mempengaruhi pengetahuan seseorang. Ibu yang bekerja cenderung memiliki banyak teman yang dapat berbagi cerita tentang pengalaman terhadap kunjungan neonatus. Dibandingkan dengan responden yang hanya menjadi ibu rumah tanggaakan selalu terfokus pada pekerjaan rumah tangga dan mengurus anak, hal ini bisa saja menjadi penyebab ibu rumah tangga tidak mendapatkan informasi tentang kunjungan neonatus dari berbagai sumber, misalnya: pengalaman (orang tua, saudara, kerabat/tetangga) media massa ( $\mathrm{TV}$, radio, internet) dan media cetak (koran, majalah).

Sedangkan responden yang bekerja tetapi mengalami kunjungan neonatus yang tidak tercapai, menurut asumsi peneliti responden terlalu sibuk bekerja sehingga tidak sempat untuk membawa anak untuk melakukan kunjungan neonatus.

\section{SIMPULAN}

Dari hasil penelitian yang dilakukan terhadap 56 orang ibu yang mempunyai bayi di Wilayah Kerja Puskesmas Lubuk Kilangan Padang pada bulan April-Mei 2016, dapat disimpulkan sebagai berikut:

Lebih separuh $(55,4 \%)$ responden yang melakukan kunjungan neonatus yang tidak tercapai. Lebih separuh $(57,1 \%)$ responden yang memiliki pengetahuan rendah tentang kunjungan neonatus. Lebih separuh $(55,4$ $\%)$ responden memiliki sikap negatif terhadap kunjungan neonates. Lebih separuh $(67,9 \%)$ responden yang tidak bekerja dan menyebabkan ibu tidak memahami tentang kunjungan neonates. Terdapat hubungan bermakna antara pengetahuan dengan Kunjungan Neonatus, nilai $\mathrm{p}=0,009$ OR $=5,111$. Terdapat hubungan bermakna antara sikap dengan Kunjungan neonatus, nilai $\mathrm{p}=0,004 \mathrm{OR}=$ 6,109 . Terdapat hubungan bermakna antara pekerjaan dengan Kunjungan Neonatus, nilai $\mathrm{p}=0,000 \mathrm{OR}=63,750$
Bagi Ibu yang memiliki bayi usia 0-28 hari Diharapkan pada Ibu yang memiliki bayi usia 0-28 hari dapat termotivasi untuk melakukan kunjungan neonatus sesuai jadwal. Ibu diharapkan rajin mencari informasi atau membaca buku yang berhubungan dengan kunjungan neonatus.Selain itu ibu diharapkan bisa menghadiri atau datang pada saat pelayanan posyandudiberikan.

Bagi Puskesmas Lubuk Kilangan

Bidan dan KaderBidan dan kader sangat berperan penting pada kunjungan neonatus ini.Diharapkan bidan dan kader dapat memberikan penyuluhan terjadwal kepada ibu-ibu pada saat pelayanan posyandu. Menyebarkan leaflet kepada masyarakat/ibu-ibu agar dapat membaca tentang manfaat dari kunjungan neonatus tersebut. Memberikan pelayanan kerumah jika ibu tidak dapat berkunjung ke posyandu.

Bidan juga perlu memberikan pelayanan home care agar kunjungan neonatus dapat tercapai dan tumbuh kembang anak dapat dipantau. Ibu bayi pun pasti merasa senang mendapatkan pelayanan homecare tersebut. Bagi Kepala PuskesmasKepala Puskesmas bisa mengkoordinasi dan memantau bawahannya, apakah pelayanan yang diberikan sudah bagus atau belum.Jika belum kepala puskesmas dapat mengarahkan bawahannya agar dapat memberikan pelayanan yang berkualitas agar tercapainya dalam kunjungan neonatus.3. Bagi Stikes Fort De Kock

Diharapkan pada pihak pendidikan agar hasil penelitian ini dapat dijadikan sebagai referensi dan acuan untuk penelitian selanjutnya.4. Bagi Peneliti Selanjutnya. Diharapkan pada peneliti selanjutnya untuk dapat meneliti variabel lain yang berhubungan dengan kunjungan neonatus. 


\section{DAFTAR PUSTAKA}

Afifah. 2013. Gambaran Pengetahuan, Sikap dan Praktik Ibu Post Natal terhadap Kunjungan Neonatus di Bps. Hj. Sri Wahyuni Kota Semarang tahun 2013.Edisi 2014, Vol 2. No 8

Darmawan, Flora Honey dkk. 2011. Hubungan Pengetahuan Ibu dan Dukungan Suami dengan Kunjungan Neonatus (KN) di Wilayah Kerja Puskesmas Pasirlagu Kabupaten Bandung Bara . Edisi 2011, Vol 13. No 25

Dinkes Bukittinggi.2015

Dinkes Provinsi Sumatra Barat. 2012

Dwienda, Octa dkk. 2014. Asuhan Kebidanan Neonatus, Bayi/ Balita dan Anak Prasekolah untuk Para Bidan. Yogyakarta: Budi Utama

Fanhatun, Mesganaw dan Alemayehu Worku. 2012. Neonatal Care Practice and Faktors Affecting ini Southwest Ethiopia. Edisi 2013, Vol 22. No 37-40

Hidayat Alimul, A. Aziz. 2009. Asuhan Neonatus Bayi dan Balita. Buku Praktikum Mahasiswa Kebidanan. EGC: Jakarta

Http://www.Dinkes.Bukittinggi.go.id (Diakses 20 Januari 2016)

Http://www.Dinkes.Sumbarprov.go.id (Diakses 18 Januari 2016)

Http://www.Kemkes.go.id (Diakses 19 Januari 2016)

Lestari, Titik. 2014. Kumpulan Teori untuk Kajian Pustaka Penelitian Kesehatan. Yogyakarta: Nuha Medika
Linggawati, Tuti. 2011. Hubungan Pengetahuan Ibu dengan Kunjungan Neonatal di Puskesmas Kota Tais. Edisi 2011, Vol 10. No 14

Maria, Rufia Desi dan Mutia Fellina. 2013.Gambaran Pengetahuan Ibu yang Mempunyai Bayi Usia 0-28 hari tentang Kunjungan Neonatus di Puskesmas Padan Kandi Kabupaten 50 Kota. Edisi 2014, Vol 5. No 1

Meilani, Niken. 2007. Kebidanan Komunitas. Yogyakarta: Fitramaya

Muslihatun, Wafi Nur. 2010. Asuhan Neonatus Bayi dan Balita. Yogyakarta: Fitramaya

Nanny, Vivian. 2012. Asuhan Neonatus Bayi dan Anak Balita. Jakarta: Salemba Medika

Notoadmodjo, Soekidjo. 2007. Promosi Kesehatan Teori dan Aplikasi. Jakarta: Rineka Cipta

Notoadmodjo, Soekidjo. 2010. Promosi Kesehatan Teori dan Aplikasi. Jakarta: Rineka Cipta

Notoadmodjo, Soekidjo. 2007. Metode Penelitian Kesehatan. Jakarta: Rineka Cipta

Notoadmodjo, Soekidjo. 2010. Metode Penelitian Kesehatan.Jakarta: Rineka Cipta

Profil Kesehatan Indonesia. 2014

Putra, Sitiatava Rizema. 2012. Asuhan Neonatus Bayi dan Balita untuk Keperawatan dan Kebidanan. Yogyakarta: Medika

Rosita, Andri. 2012. Gambaran Persepsi Ibu tentang Kelengkapan Pemeriksaan saat Kunjungan Neonatus di Kec Poncoworno 
Kabupaten Kebumen. Edisi 2012, Vol 24. No 13

Saifuddin, Abdul Bahri dkk. 2006. Buku Acuan Nasional Pelayanan Kesehatan Maternal dan Neonatal

Tafany, 2007. Kematian Neonatus. Jakarta (Diakses 20 Januari 2016)

Yulifah, Rita. 2013. Asuhan Kebidanan Komunitas. Jakarta: Salemba Medika 